\title{
Outcome of Primary Intracerebral Hemorrhage: A Study in Tertiary Care Center
}

\author{
Jagat Narayan Rajbanshi' ${ }^{1}$, Pankaj Raj Nepal ${ }^{1}$ \\ ${ }^{1}$ Department of Neurosurgery, B and C Medical College Teaching Hospital and Research Center, Birtamode, \\ Jhapa.
}

\author{
Correspondence: \\ Dr. Jagat Narayan Rajbanshi, \\ Department of Neurosurgery, \\ B and C Medical College Teaching Hospital and Research Center, Birtamode, Jhapa, Nepal \\ Phone number: +9779818101187 \\ Email: sergiorajbanshi@gmail.com
}

\begin{abstract}
Background: Intracerebral hemorrhage (ICH) is an irreversible phenomenon inside the brain parenchyma resulting in mild to severe neurological deficit. Based on etiology it is broadly divided into primary and secondary. Primary ICH is usually due to the rupture of Charcot-Bouchard aneurysm and chronic hypertension. Charcot - Bouchard aneurysms are supposed to get formed due to lipohyalinosis. With the aim to evaluate the outcome of primary ICH admitted to our institute this study is performed.Materials and methods: This is a prospective analytical study, where all the consecutive patients of the primary ICH were collected. Quantitative variables like age, the volume of hematoma, midline shift, GCS, and systolic blood pressure (SBP) were presented as mean and standard deviation (S.D). Whereas, qualitative variables like gender, site, and side of hematoma, type of treatment, best motor response were presented in frequency and percentage. The outcome of the patient was measured using the Glasgow outcome scale (GOS) and the association between qualitative/quantitative variables and GOS was done using the chi-square test or Fischer exact test whenever applicable in SPSS20. Results: There were a total of 31 patients with a mean age of 59.81(S. D 15.8) year and male predominance (74\%). The mean volume of hematoma was $40 \mathrm{ml}$. Similarly, midline shift ranged from zero to $14 \mathrm{~mm}$. The majority of primary ICH were located in basal ganglia (35\%) and on the right side (52\%). The mean GCS at presentation was 12.1 (S.D 2.166). Mean Systolic blood pressure was $163.77 \mathrm{mmHg}$ (S.D $34.6 \mathrm{mmHg}$ ) with maximum SBP up to $240 \mathrm{mmHg}$. There was a $14 \%$ mortality in this study group with favorable outcome (GOS 4 and 5) in $82 \%$. GOS was significantly associated with the volume of hematoma and midline shift. Conclusion: The outcome of primary ICH is strongly associated with the volume of hematoma and midline shift. They were generally associated with hypertension with a mean systolic blood pressure of $>160 \mathrm{~mm} \mathrm{Hg}$.
\end{abstract}

Key words:Glasgow outcome scale, Intracerebral hemorrhage, Midline shift, Outcome.

I ntracerebral hemorrhage ( $\mathrm{ICH})$ is an irreversible phenomenon inside the brain parenchyma resulting in mild to severe neurological deficit. ${ }^{1}$ Based on etiology it is broadly divided into primary and secondary. ${ }^{2,3}$ Primary ICH is usually due to the rupture of Charcot-Bouchard aneurysm and chronic hypertension. Charcot - Bouchard aneurysms are supposed to get formed due to lipohyalinosis. ${ }^{4,5}$ Secondary ICH are due to trauma, tumors, AVM, AVF, aneurysms, coagulopathy, amyloid angiopathy, drug-induced, and so on. ${ }^{3}$ Controversy still exists in the management of primary ICH. Its management range from conservative to various surgical treatment. ${ }^{6-11}$ Treatment is also based on the patient's GCS, age, amount of hematoma, site, and side of the hematoma. ${ }^{6,8}$ With the aim to evaluate the outcome of primary ICH admitted to our institute this study is performed.

\section{Methods and Materials:}

Type of study: Prospective analytical study

Sampling technique: Non-probability consecutive sampling 
Sample size: 31 patients

Duration: 4 months

Site of study: B\&C Medical College Teaching Hospital and Research Centre, Birtamode, Jhapa, Nepal.

Data collection and analysis:All the consecutive patients of the primary ICH were collected during the study period and data collection was done in preformed Performa. Quantitative variables like age, the volume of hematoma, midline shift, GCS, and systolic blood pressure (SBP) were presented as mean and standard deviation (S.D). Whereas, qualitative variables like gender, site, and side of hematoma, type of treatment, best motor response were presented in frequency and percentage. The outcome of the patient was measured using the Glasgow outcome scale (GOS) and an association between qualitative/quantitative variables and GOS was done using a chi-square test or Fischer exact test whenever applicable in SPSS 20.

\section{Results:}

There were a total of 31 patients among which three patients left treatment against medical advice, the mean age of the total patients was 59.81(S. D 15.8) years (Table 1).

Table 1: Mean and standard deviation of quantitative variables.

\begin{tabular}{lccccc}
\hline & N & $\begin{array}{c}\text { Minimu } \\
\mathbf{m}\end{array}$ & $\begin{array}{c}\text { Maximu } \\
\mathbf{m}\end{array}$ & $\begin{array}{c}\text { Mea } \\
\mathbf{n}\end{array}$ & $\begin{array}{c}\text { Std. } \\
\text { Deviatio } \\
\end{array}$ \\
& & & & & $\mathbf{n}$ \\
\hline Age & 31 & 26 & 84 & 59.81 & 15.800 \\
Volume & 26 & 5 & 90 & 38.60 & 23.250 \\
Midline & 31 & 0 & 14 & 4.13 & 4.248 \\
shift & & & & & \\
SBP & 31 & 110 & 240 & 163.71 & 34.640 \\
$\begin{array}{l}\text { Presenting } \\
\text { GCS }\end{array}$ & 31 & 7 & 15 & 12.10 & 2.166 \\
& & & & &
\end{tabular}

There were $74 \%$ male and $26 \%$ female (Figure 1).

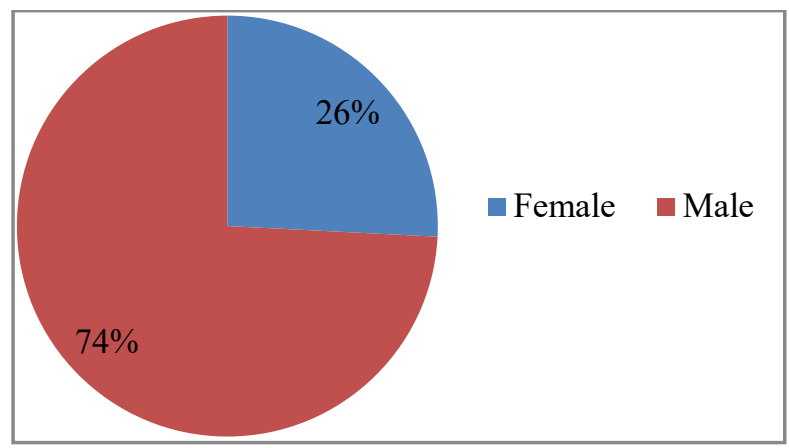

Figure 1: Distribution of gender

The volume of the hematoma in this study ranged from five to $90 \mathrm{ml}$ with a mean volume of $40 \mathrm{ml}$. The majority of the amount of volume was below $50 \mathrm{ml}$ (Figure 2).

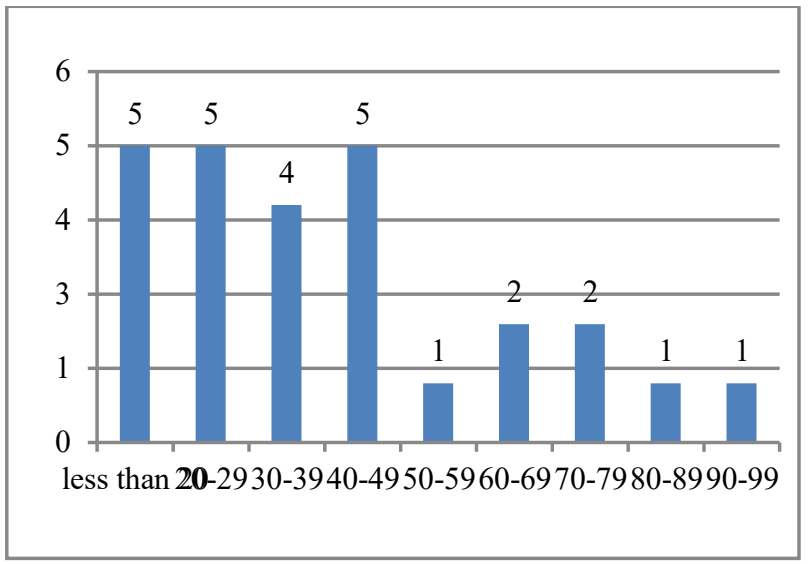

Figure 2: Frequencies of patients with different groups of the volume of blood.

Similarly, midline shift ranged from zero to $14 \mathrm{~mm}$ (Table 1).The majority of primary ICH were located in basal ganglia (35\%) followed by lobar (29\%) (Figure 3) and most of them on the right side $(52 \%)$ (Figure 4). 


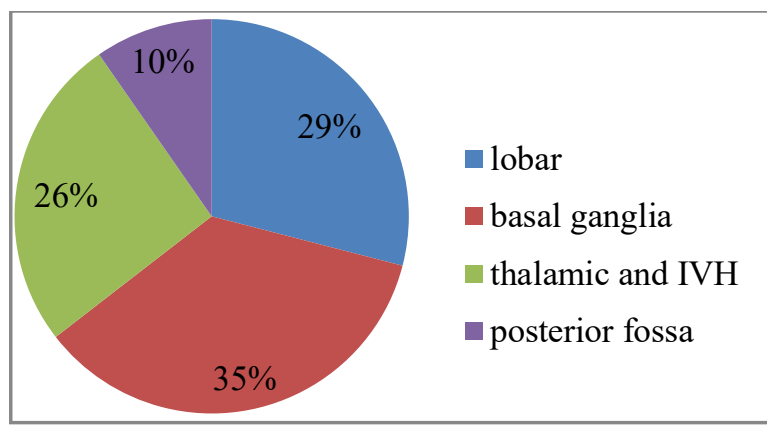

Figure 3: Distribution of ICH in different locations

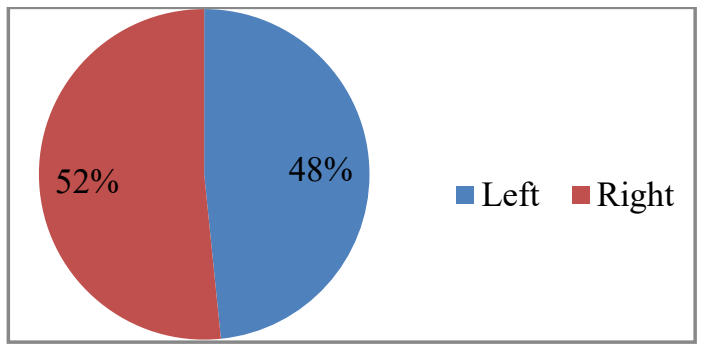

Figure 4: Distribution of ICH on different sides.

The mean GCS at presentation was 12.1 (S.D 2.166). Out of a total of 31 patients three patients left treatment against medical advice, nine patients underwent surgical evacuation of hematoma and 2 patients underwent external ventricular drainage for intraventricular bleed with hydrocephalus; however, rest of them were managed conservatively.

The majority of the patients had the best motor response of 5 and 6 with GCS maintaining 11 and above at the time of presentation (Figure 5 and Figure 6).

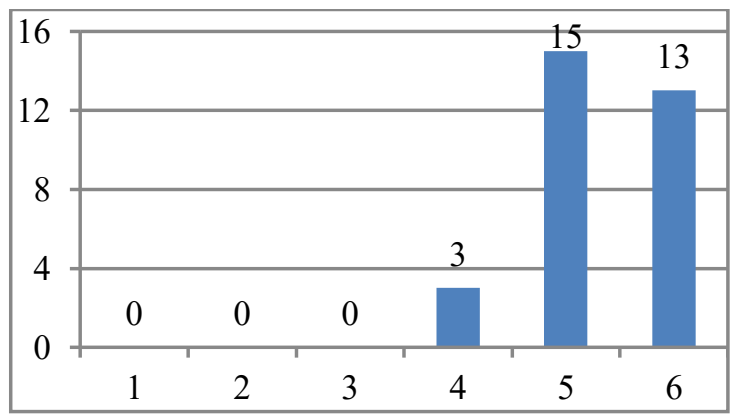

Figure 5: Frequencies of best motor response at the time of presentation. egneuro, Volume 02, Issue 02, 2020

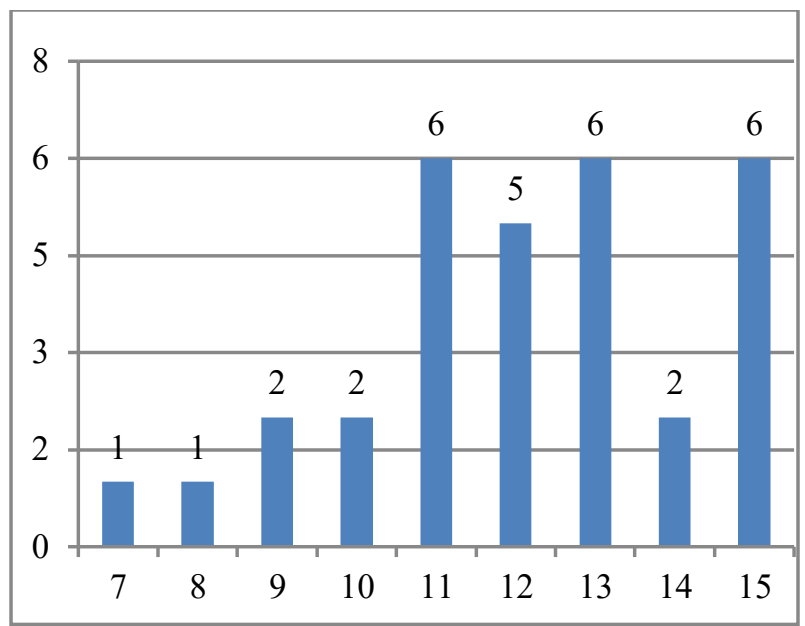

Figure 6: Frequencies of total GCS at the time of presentation.

Mean Systolic blood pressure was $163.77 \mathrm{mmHg}$ (S.D $34.6 \mathrm{mmHg}$ ) with maximum SBP up to $240 \mathrm{mmHG}$ (Table 1). There was a $14 \%$ mortality in this study group with favorable outcome (GOS 4 and 5) in $82 \%$ (Figure 7).

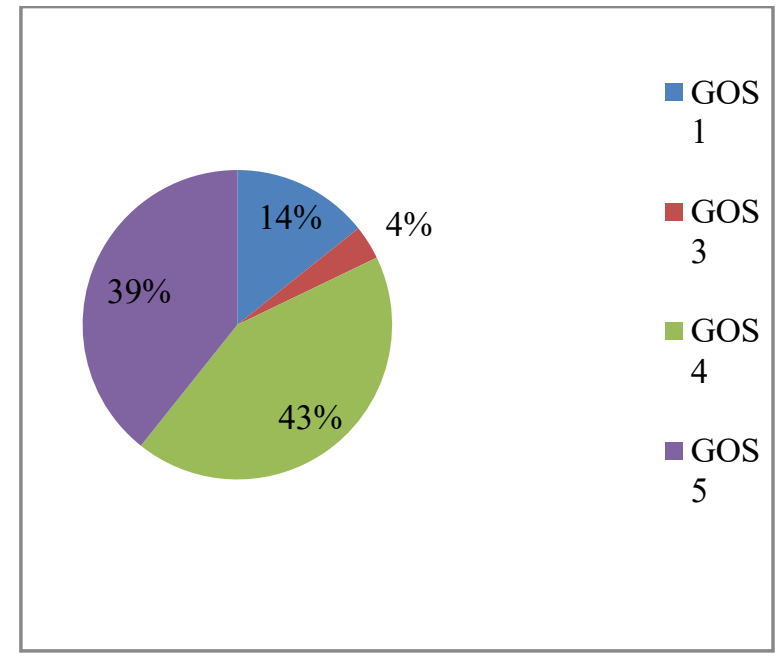

Figure 7: Glasgow outcome at 3 months

GOS was significantly associated with the volume of hematoma and midline shift, where smaller volume was associated with better outcome and greater midline shift with poor outcome (Table 2 and Table 3). 
Table 2: Association of different continuous variables with the outcome

\begin{tabular}{llccc}
\hline \multicolumn{4}{c}{ One-way ANOVA for the continuous data } & \\
& N & Mean & Std. Deviation & PValue \\
\hline Age & 31 & 59.81 & 15.8 & .427 \\
Volume & 26 & 38.6 & 23.25 & $\mathbf{. 0 0 0}$ \\
Midlineshift & 31 & 4.13 & 4.248 & $\mathbf{. 0 2 3}$ \\
SBP & 31 & 163.71 & 34.64 & .992 \\
GCS & 31 & 12.1 & 2.166 & .108 \\
\hline
\end{tabular}

\section{Discussion:}

Primary intracerebral hemorrhage is a pathology carrying a grave prognosis with no promising outcome throughout the world. ${ }^{6,7}$ Despite a large randomized trial conducted to find the best treatment strategy, they still seem to be non-satisfactory. In the bigger trial, the mortality rate of primary ICH is around 40$60 \%$ with different treatment modalities. ${ }^{6,7,12,13}$ In this study the poor outcome was around $18 \%$, this finding seems to be less than the bigger trials which might be due to the small sample size and maximum numbers of patients with bleed less than 50\%. However, the volume of hematoma seems to be significantly associated with the outcome of the patient which is consistent with previous studies, midline shift which is the marker of ongoing herniation is a good tool in prognosticating the clinical outcome of the patient in the previous study, midline shift of more than $5 \mathrm{~mm}$ are considered significant in a clinical setting. ${ }^{6,7,14,15}$ In our study, a maximum of 14 $\mathrm{mm}$ midline shift was noted with a mean of $4.13 \mathrm{~mm}$ and it was significantly associated with poor outcome of the patient.

\section{Conclusion:}

The outcome of primary ICH is strongly associated with the volume of hematoma and midline shift. They were generally associated with hypertension with a mean systolic blood pressure of $>160 \mathrm{~mm}$ $\mathrm{Hg}$. 
Table 3: Association of different categorical variables with the outcome.

\begin{tabular}{|c|c|c|c|c|c|c|c|}
\hline & & \multicolumn{4}{|c|}{ GOS } & \multirow{2}{*}{ Total } & \multirow{2}{*}{ PValue } \\
\hline & & 1 & 3 & 4 & 5 & & \\
\hline \multirow[t]{2}{*}{ gender } & female & 0 & 1 & 5 & 2 & 8 & 0.162 \\
\hline & male & 4 & 0 & 7 & 9 & 20 & \\
\hline \multirow[t]{9}{*}{ volume category } & less than 20 & 0 & 0 & 0 & 4 & 4 & 0.002 \\
\hline & $20-29$ & 0 & 0 & 1 & 4 & 5 & \\
\hline & $30-39$ & 0 & 0 & 2 & 2 & 4 & \\
\hline & $40-49$ & 2 & 0 & 3 & 0 & 5 & \\
\hline & $50-59$ & 0 & 0 & 1 & 0 & 1 & \\
\hline & $60-69$ & 0 & 0 & 2 & 0 & 2 & \\
\hline & $70-79$ & 0 & 0 & 1 & 0 & 1 & \\
\hline & $80-89$ & 0 & 1 & 0 & 0 & 1 & \\
\hline & $90-99$ & 1 & 0 & 0 & 0 & 1 & \\
\hline \multirow[t]{4}{*}{ site of Lesion } & lobar & 1 & 1 & 2 & 5 & 9 & 0.396 \\
\hline & basal ganglia & 2 & 0 & 6 & 2 & 10 & \\
\hline & $\begin{array}{c}\text { Thalamicand } \\
\text { IVH }\end{array}$ & 1 & 0 & 4 & 2 & 7 & \\
\hline & posterior fossa & 0 & 0 & 0 & 2 & 2 & \\
\hline \multirow[t]{2}{*}{ Side of lesion } & Left & 1 & 1 & 6 & 5 & 13 & 0.765 \\
\hline & Right & 3 & 0 & 6 & 6 & 15 & \\
\hline \multirow{3}{*}{$\begin{array}{l}\text { Motor response on } \\
\text { presentation }\end{array}$} & 4 & 1 & 0 & 0 & 1 & 2 & 0.600 \\
\hline & 5 & 1 & 1 & 7 & 5 & 14 & \\
\hline & 6 & 2 & 0 & 5 & 5 & 12 & \\
\hline \multirow[t]{3}{*}{ Treatment provided } & Conservative & 1 & 0 & 7 & 9 & 17 & 0.166 \\
\hline & EVD & 1 & 0 & 1 & 0 & 2 & \\
\hline & $\begin{array}{c}\text { surgical } \\
\text { evacuation }\end{array}$ & 2 & 1 & 4 & 2 & 9 & \\
\hline ferences: & & & & ger & $\begin{array}{l}\text { race } \\
\text { th. } \\
503 .\end{array}$ & $\begin{array}{l}\text { ral hemorr } \\
\text { itical ca }\end{array}$ & $\begin{array}{l}\text { pathophysiology } \\
\text { medicine. } 1993\end{array}$ \\
\hline
\end{tabular}


2. Sutherland GR, Auer RN. Primary intracerebral hemorrhage. Journal of Clinical Neuroscience. 2006 Jun 1;13(5):511-7.

3. Meretoja A, Strbian D, Putaala J, Curtze S, Haapaniemi E, Mustanoja S, Sairanen T, Satopää J, Silvennoinen H, Niemelä M, Kaste M. SMASH-U: a proposal for etiologic classification of intracerebral hemorrhage. Stroke. 2012 Oct;43(10):2592-7.

4. Charcot JM, and Bouchard C. Arch. Physiol. 1868; norm, path., 1,110, 643 and 723 .

5. Challa VR, Moody DM, Bell MA. The Charcot-Bouchard aneurysm controversy: impact of a new histologic technique. Journal of neuropathology and experimental neurology. 1992 Mar 1;51(3):264-71.

6. Mendelow AD, Gregson BA, Fernandes HM, Murray GD, Teasdale GM, Hope DT, Karimi A, Shaw MD, Barer DH, STICH investigators. Early surgery versus initial conservative treatment in patients with spontaneous supratentorial intracerebral haematomas in the International Surgical Trial in Intracerebral Haemorrhage $(\mathrm{STICH})$ : a randomised trial. The Lancet. 2005 Jan 29;365(9457):387-97.

7. Mendelow AD, Gregson BA, Rowan EN, Murray GD, Gholkar A, Mitchell PM, STICH II Investigators. Early surgery versus initial conservative treatment in patients with spontaneous supratentorial lobar intracerebral haematomas (STICH II): a randomised trial. The Lancet. 2013 Aug 3;382(9890):397-408.

8. Vespa P, Hanley D, Betz J, Hoffer A, Engh J, Carter R, Nakaji P, Ogilvy C, Jallo J, Selman W, Bistran-Hall A. ICES (Intraoperative Stereotactic Computed TomographyGuided Endoscopic Surgery) for brain hemorrhage: a multicenter randomized controlled trial. Stroke. 2016 Nov;47(11):2749-55.

9. Morgan T, Zuccarello M, Narayan R, Keyl P, Lane K, Hanley D. Preliminary findings of the minimally-invasive surgery plus rtPA for intracerebral hemorrhage evacuation (MISTIE) clinical trial. InCerebral Hemorrhage 2008 (pp. 147-151). Springer, Vienna.

10. Hemphill JC, Bonovich DC, Besmertis L, Manley GT, Johnston SC. The ICH score. Stroke. 2001 Apr;32(4):8917.

11. Dunatov S, Antoncic I, Bralic M, Jurjevic A. Intraventricular thrombolysis with rt-PA in patients with intraventricular hemorrhage. Acta neurologica scandinavica. 2011 Nov;124(5):343-8.

12. González-Pérez A, Gaist D, Wallander MA, McFeat G, García-Rodríguez LA. Mortality after hemorrhagic stroke: data from general practice (The Health Improvement Network). Neurology. 2013 Aug 6;81(6):559-65.

13. Flaherty ML, Haverbusch M, Sekar P, Kissela B, Kleindorfer D, Moomaw CJ, Sauerbeck L, Schneider A, Broderick JP, Woo D. Long-term mortality after intracerebral hemorrhage. Neurology. 2006 Apr 25;66(8):1182-6.

14. Bhattathiri PS, Gregson B, Prasad KS, Mendelow AD. Intraventricular hemorrhage and hydrocephalus after spontaneous intracerebral hemorrhage: results from the STICH trial. InBrain Edema XIII 2006 (pp. 65-68). Springer, Vienna.
15. Hallevy C, Ifergane G, Kordysh E, Herishanu Y. Spontaneous supratentorial intracerebral hemorrhage. Journal of neurology. 2002 Dec 1;249(12):1704-9.

16. Chiquete E, Ochoa-Guzmán A, Vargas-Sánchez Á, Navarro-Bonnet J, Andrade-Ramos MA, GutiérrezPlascencia P, Ruiz-Sandoval JL. Blood pressure at hospital admission and outcome after primary intracerebral hemorrhage. Archives of medical science: AMS. 2013 Feb 21;9(1):34.

17. Arima H, Wang JG, Huang Y, Heeley E, Skulina C, Parsons MW, Peng B, Li Q, Su S, Tao QL, Li YC. Significance of perihematomal edema in acute intracerebral hemorrhage: the INTERACT trial. Neurology. 2009 Dec 8;73(23):1963-8.

18. Rosenow F, Hojer CH, Meyer-Lohmann C, Hilgers RD, Miihlhofer H, Kleindienst A, Owega A, Koning W, Heiss WD. Spontaneous intracerebral hemorrhage. Acta neurologica scandinavica. 1997 Sep;96(3):174-82. 